\title{
Study of the Electrochemical Behaviour of Tolitriazole in Phosphating Bathings of Carbon Steel 1008
}

\author{
Everson P. Banczek, Marilei F. Oliveira, Maico T. Cunha, \\ Paulo R.P. Rodrigues*
}

GPEL - Group of Research in Electrochemistry - DEQ - Department of Chemistry of UNICENTRO - State University of the Center-West (PR), Guarapuava, Paraná - Brazi

Received 15 April 2004; accepted in revised form 23 September 2004

\begin{abstract}
The characteristics of corrosion inhibitors of the tolitriazole (TTA) for the carbon steel 1008 , covered by zinc or tricationic phosphate (Mn, $\mathrm{Zn}, \mathrm{Ni}$ ), in the means of $\mathrm{H}_{2} \mathrm{SO}_{4} 0.1$ mol $\mathrm{L}^{-1}$ and $\mathrm{NaCl} 0.5 \mathrm{~mol} \mathrm{~L}^{-1}$, were investigated by physical and electrochemical methods. The results obtained in the absence of the inibidor TTA showed that the corrosion protection properties of the tricationic phosphate (Ptri) are better than those observed for the zinc phosphate (PZn), probably due to the presence of vacancies in the layer of PZn. The curves of anodic polarization presented current densities (j) smaller for the steel phosphatized with Ptri, when compared with the metal substrate without phosphate and with PZn. The results of impedance electrochemistry (IE) showed a polarization resistance $(\mathrm{Rp})$ larger for the electrodes phosphatized with Ptri. The electrochemistry measurements of the samples of steel phosphatized, with PZn and/or Ptri, in the presence of $[$ TTA $]=1 \times 10^{-3} \mathrm{~mol} \mathrm{~L}^{-1}$, present smaller $\mathrm{j}$ and larger Rp when compared with the absence of TTA. In the process of phosphatization of the carbon steel with PZn + TTA, it was observed similar $\mathrm{j}$ and $\mathrm{Rp}$ in the samples of steel phosphatized with Ptri without TTA. These results suggest that the bathing of zinc phosphate with $\left[\right.$ TTA] $=1 \times 10^{-3} \mathrm{~mol} \mathrm{~L}^{-1}$ can substitute the well known industrial bathing of tricationic phosphate. Corrosion testing by Salt Spray of steel phosphatized with PZn and PZn + TTA, painted with white polyester ink, confirmed the eletrochemical results.
\end{abstract}

Keywords: tolitriazole, corrosion, phosphatization, inhibitors.

\footnotetext{
* Corresponding author. E-mail address: PRPRodrigues@unicentro.br
} 


\section{Introdução}

A exposição dos metais a diferentes meios agressivos tem levado a pesquisas a constantes buscas de formas de inibição do processo corrosivo destes metais. A fosfatização [1-6] é uma das técnicas de tratamento de superfície de metais ferrosos e não ferrosos mais conhecidas industrialmente.

Existem vários fatores que podem influenciar [9] o processo de fosfatização de metais, podendo aumentar ou até diminuir a vida útil da peça metálica, como a composição do banho de fosfatização, concentração, temperatura e até as condições da superfície metálica que sofrerá o tratamento.

Nas indústrias em geral empregam os banhos de fosfato de zinco ou os multicatiônicos, como por exemplo, os de fosfato de zinco e manganês [1] ou fosfato tricatiônico ( $\mathrm{Zn}, \mathrm{Ni}$ e $\mathrm{Mn}$ ) [1,10,11]. O banho tricatiônico é o mais empregado industrialmente $[8,12]$ devido a sua maior eficiência na inibição da corrosão; contudo, é o de maior custo e o mais oneroso quanto ao tratamento do descarte industrial devido a presença de metais pesados. Na atualidade os banhos de fosfatização inorgânicos vêm sendo substituídos por banhos orgânicos [1], relatados como "ecologicamente corretos".

Este trabalho tem como objetivo adicionar um composto orgânico aos banhos de fosfato de zinco e tricatiônico, com intuito de se melhorar o desempenho no processo inibidor da corrosão do metal base, além de se diminuir uma das etapas existentes na indústria de tratamento de superfície, quando se emprega o inibidor de corrosão. O composto orgânico escolhido para este trabalho é o tolitriazol (TTA) Fig. 1, devido ao seu relatado [13] caráter inibidor misto (atuando tanto como inibidor anódico, quanto catódico).

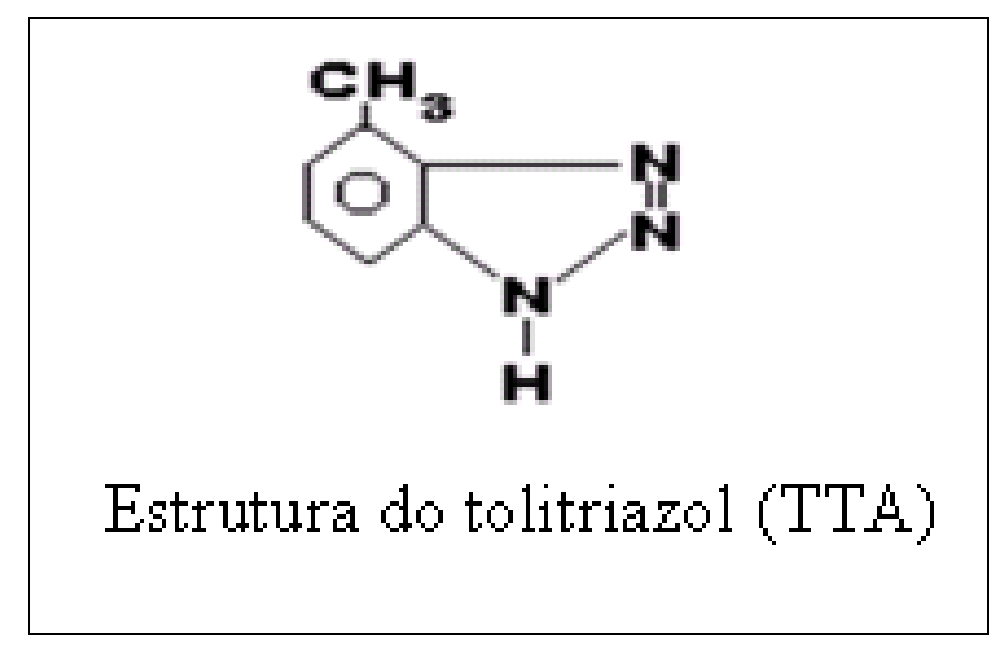

Figura 1. Representação do TTA.

\section{Parte experimental}

Substrato metálico, banho de fosfato e soluções

O aço carbono ABNT 1008 foi empregado como substrato metálico, sendo a sua composição química mostrada na Tabela 1. 
Tabela 1. Composição química média da superfície do aço carbono 1008.

\begin{tabular}{|c|c|c|c|c|c|c|c|c|}
\hline Elemento & $\mathbf{C}$ & $\mathbf{M n}$ & $\mathbf{P}$ & $\mathbf{S}$ & $\mathbf{N i}$ & $\mathbf{Z n}$ & $\mathbf{C r}$ & $\mathbf{F e}$ \\
\hline $\boldsymbol{\%} \mathbf{~ m} / \mathbf{m}$ & 0.08 & 0.330 & 0.048 & 0.021 & 0.410 & 0.070 & 0.060 & 99.029 \\
\hline
\end{tabular}

Para o banho de PZn e Ptri ( $\mathrm{Zn}, \mathrm{Ni}, \mathrm{Mn})$ foram utilizados reagentes de grau industrial e água destilada.

As soluções de $\mathrm{H}_{2} \mathrm{SO}_{4} 0.1 \mathrm{~mol} \mathrm{~L}^{-1}$ e $\mathrm{NaCl} 0.5 \mathrm{~mol} \mathrm{~L}^{-1}$ sem e com tolitriazol (TTA) $1.10^{-3} \mathrm{~mol} \mathrm{~L}^{-1}$ foram preparadas com água bi-destilada e reagentes de grau analítico.

O processo de fosfatização das peças de aço carbono 1008 é executado em cinco etapas:

$1^{\text {a }}$ etapa - tratamento de superfície: Realiza-se um tratamento superficial da peça em politriz com lixa de $\mathrm{SiC}$ de grana 600; em seguida procede-se com etapas de enxágüe e secagem para posterior medida da massa do corpo de prova metálico em balança analítica.

$2^{\text {a }}$ etapa - tratamento de desengraxamento: O banho desengraxante é composto por $30 \%$ de soda caustica, $28 \%$ de metasilicato de sódio, $20 \%$ de fosfato trisódio, $5 \%$ barrilha leve, $1 \%$ de querosene e $2 \%$ de tamol. $\mathrm{O}$ desengraxamento inicia-se aquecendo o banho desengraxante até aproximadamente $85{ }^{\circ} \mathrm{C}$; segue-se a imersão da peça por 5 minutos, para total remoção das sujidades da superfície da amostra metálica. Na seqüência realiza-se o enxágüe em água corrente.

$3^{\text {a }}$ etapa - tratamento de ativação da superfície: Após o desengraxamento a peça é imersa na solução de ativação por 90 segundos. A composição básica do ativador é dióxido de titânio $3 \mathrm{~g} / \mathrm{L}$, em água.

$4^{\mathrm{a}}$ etapa - fosfatização: O banho de PZn é composto por $32.4 \%$ de ácido fosfórico, $0.5 \%$ de carbonato de níquel, $16 \%$ de óxido de zinco, $23 \%$ de ácido nítrico, $0.1 \%$ de peróxido de hidrogênio e $28 \%$ de água. $\mathrm{O}$ banho de Ptri é composto por $19,7 \%$ de ácido fosfórico, $6.9 \%$ de ácido nítrico concentrado, $1.9 \%$ de carbonato de manganês, $7 \%$ de óxido de zinco, $1 \%$ de carbonato de níquel, $0.07 \%$ de ácido fluorídrico, $0.03 \%$ de hidrazina e $63.4 \%$ de água.

Para fosfatização a peça metálica é imersa em banho de PZn ou Ptri em temperatura média de $25{ }^{\circ} \mathrm{C}$, permanecendo por 5 minutos, obtendo-se a camada de PZn ou Ptri sobre a superfície da peça metálica.

$5^{\text {a }}$ etapa - limpeza: Retira-se a peça do banho de fosfato submetendo esta a um novo enxagüe em água corrente seguida de secagem em estufa a $80{ }^{\circ} \mathrm{C}$. A partir do valor da massa obtida para a peça metálica fosfatizada e do valor de massa previamente obtido antes das etapas de ativação e fosfatização, calcula-se a massa da camada de fosfato depositado.

$6^{a}$ etapa - pintura: Após a etapa de fosfatização as peças metálicas foram submetidas a um processo de pintura eletrostática a base de tinta poliéster em pó de cor branca. Após a pintura as peças foram submetidas a ensaios em câmera de Salt Spray. A tinta escolhida é a mesma empregada industrialmente na fabricação de eletrodomésticos. 
Caracterização física e eletroquímica

A composição química das camadas de PZn e Ptri e da superfície do substrato metálico foi executada por energia de dispersão de raios-X, sistema de análise EDAX do microscópio eletrônico de varredura, (MEV) Philips XX modelo V.

As curvas de polarização potenciodinamicas anódicas foram executadas com um potenciostato /galvanostato PC4-300 da Gamry Instruments, a uma velocidade de varredura de $1 \mathrm{mVs}^{-1}$, empregando-se como eletrodos: de trabalho, o aço carbono 1008, de referência, o sulfato mercuroso (ESM) e/ou prata/cloreto de prata $(\mathrm{AgCl} / \mathrm{Ag})$, e eletrodo auxiliar, de platina com área geométrica de $30 \mathrm{~cm}^{2}$.

Os eletrodos de trabalho empregados nos ensaios eletroquímicos apresentam área geométrica de $2 \mathrm{~cm}^{2}$, enquanto que as peças empregadas nos ensaios gravimétricos apresentam área geométrica de $205 \mathrm{~cm}^{2}$.

Para as medidas nos ensaios gravimétricos empregou-se uma balança analítica com precisão de $8.10^{-4} \mathrm{~g}$.

Os diagramas de impedância eletroquímica foram obtidos através de um analisador de frequiência da Gamry, modelo EIS 300, acoplado ao potenciostato PC4-300. O potencial de perturbação foi de $\pm 5 \mathrm{mV}$.

As análises de superfície foram realizadas por meio de microscópio óptico Olympus modelo BX41RF, e por microscopia eletrônica de varredura MEV.

As análises em câmara Salt Spray foram feitas por um período de exposição de 500 horas a uma temperatura de $45^{\circ} \mathrm{C}$, de acordo com a norma ASTM D1654, equivalente a (NBR-8094).

\section{Resultados e discussões}

Análise química das camadas de fosfato

A composição química das camadas de fosfato de zinco e tricatiônico aplicados na superfície do aço carbono ABNT 1008 é apresentada na Tabela 2.

Tabela 2. Composição química média das camadas de fosfato de zinco e tricatiônico obtida através da técnica de energia dispersiva (EDAX -MEV).

\begin{tabular}{|l|c|c|c|c|c|c|}
\hline $\begin{array}{l}\text { Fosfato Camada de } \\
\text { Elemento }(\% \mathrm{~m} / \mathbf{m})\end{array}$ & $\mathbf{P}$ & $\mathrm{Zn}$ & $\mathrm{Mn}$ & $\mathrm{Ni}$ & $\mathbf{F e}$ & $\mathbf{C r}$ \\
\hline zinco & 19.08 & 52.05 & 0.41 & 0.42 & 28.72 & 0.02 \\
\hline tricatiônico & 23.49 & 45.23 & 2.96 & 1.52 & 26.54 & 0.02 \\
\hline
\end{tabular}

Os resultados da tabela mostram que o fosfato de tricatiônico além do elemento zinco, contém em sua formulação os elementos manganês e níquel.

Análise gravimétrica

Nas Fig. 2 e 3, são apresentados os resultados das análises gravimétricas da massa média das camadas de fosfato. 


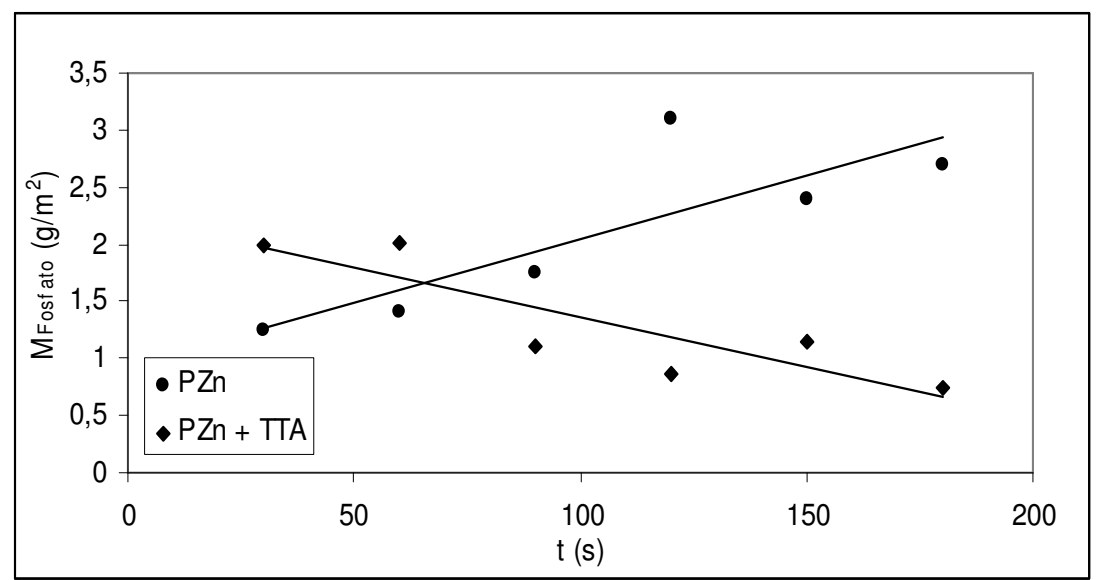

Figura 2. Massa média da camada de $\mathrm{P} Z n$ depositada sobre o aço 1008, em função do tempo de imersão $\left(\mathrm{t}_{\mathrm{i}}\right)$, em banho ativador.

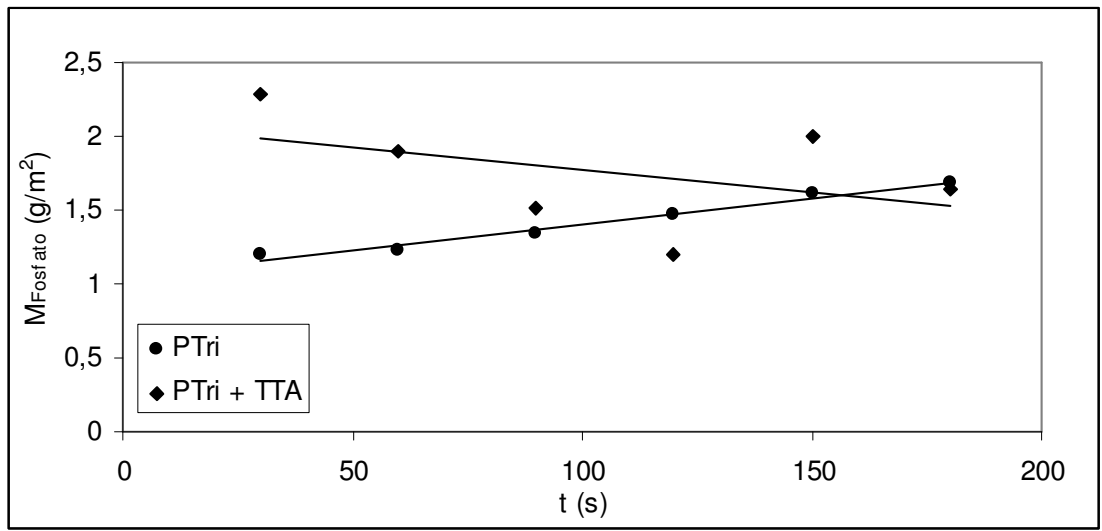

Figura 3. Massa média da camada de $\mathrm{P} Z n$ depositada sobre o aço 1008, em função do tempo de imersão $\left(\mathrm{t}_{\mathrm{i}}\right)$, em banho ativador.

Observa-se nas Fig. 2 e 3 que há um aumento das camadas de fosfato de zinco e tricatiônico, quando se aumenta o tempo de pré-imersão para ativação com $\mathrm{TiO}_{2}$ da superfície do aço carbono ABNT 1008. Na presença do tolitriazol (TTA) nota-se uma pequena diminuição desta camada, sugerindo uma competição entre a fosfato e o TTA; entretanto a espessura média das camadas de fosfato, em um tempo de imersão de noventa segundos, fica dentro do limite otimizado industrialmente [2]. Apesar da atuação inibidora do TTA ser de caráter misto (atuando tanto como inibidor catódico, quanto anódico $[1,3]$ ), este resultado era esperado.

Curvas de polarização potenciodinâmicas anódicas

Nas Fig. 4 e 5, são apresentadas as curvas de polarização potenciodinâmicas anódicas nos meios ácido $\left(\left[\mathrm{H}_{2} \mathrm{SO}_{4}\right]=0.1 \mathrm{~mol} \mathrm{~L}^{-1}\right)$ e neutro $([\mathrm{NaCl}]=0.5 \mathrm{~mol}$ $\mathrm{L}^{-1}$ ), para o aço carbono ABNT 1008 sem e com camada de fosfato de zinco e tricatiônico, na ausência e presença de $[\mathrm{TTA}]=1.10^{-3} \mathrm{~mol} \mathrm{~L}^{-1}$. 
(a)

Meio ácido

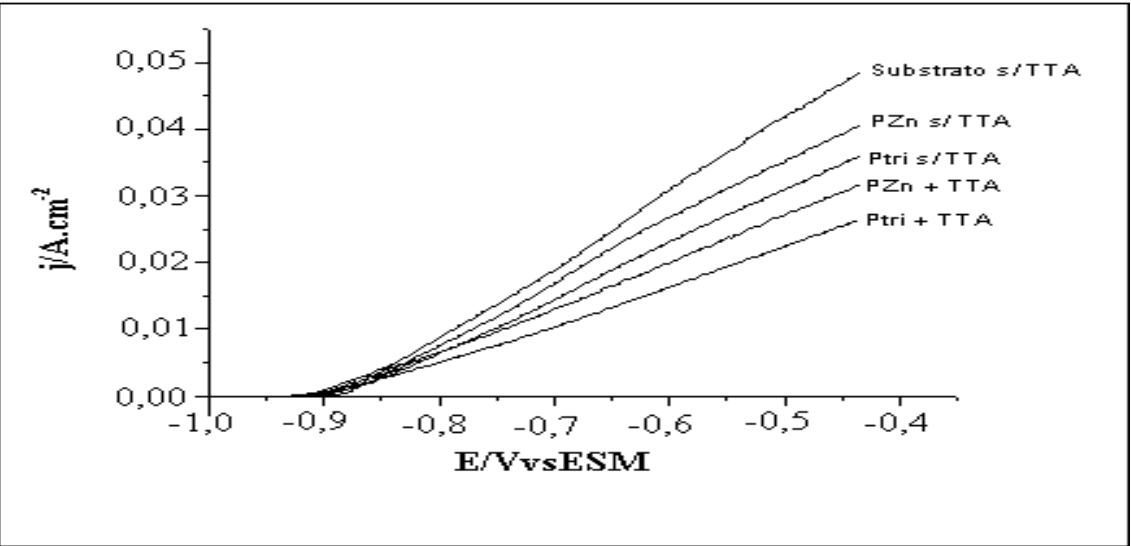

Figura 4. Curvas potenciodinâmicas de polarização anódica para diferentes substratos de aço $1008 \mathrm{em} \mathrm{H}_{2} \mathrm{SO}_{4} 0.1 \mathrm{~mol} \mathrm{~L}^{-1}$, v.v.: $1 \mathrm{mVs}^{-1}$.

Mediante a Fig. 4, verifica-se que os resultados em meio ácido mostram que há uma diminuição da densidade de corrente por toda a região de potencial anódico estudada, comparando-se os resultados dos substratos fosfatizados em relação ao sem fosfatização. Ressalta-se que ao se inserir o TTA na camada de fosfato de zinco, os valores de densidade de corrente são menores do que os observados para os substratos contendo fosfato de zinco ou tricatiônico. O substrato que apresentou melhor eficiência inibidora, em relação aos menores valores de densidade de corrente, foi o de aço carbono ABNT 1008 contendo fosfato tricatiônico com TTA.

(b) Meio neutro

Os resultados apresentados na Fig. 5, são semelhantes aos relatados anteriormente para o meio ácido, confirmando que os substratos contendo camadas de fosfato de zinco ou tricatiônico na presença de TTA, apresentaram melhor eficiência inibidora em relação aos outros substratos citados na Fig. 4.

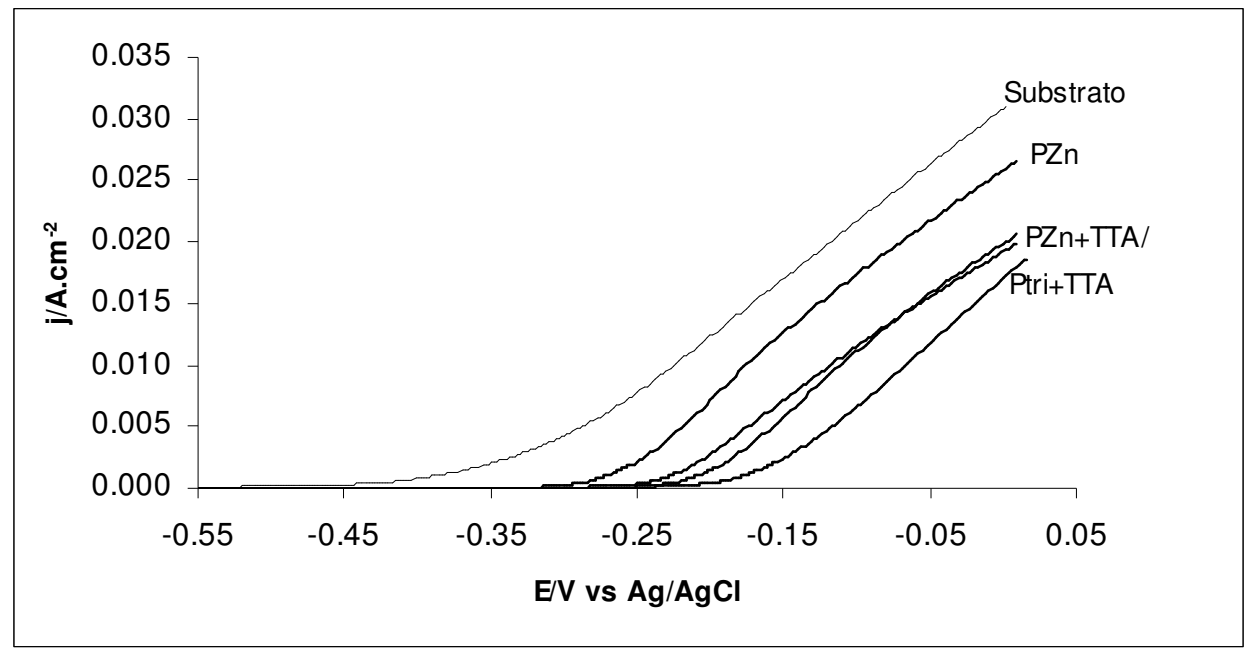

Figura 5. Curvas potenciodinâmicas de polarização anódica para diferentes substratos de aço 1008 em $\mathrm{NaCl} 0.5 \mathrm{~mol} \mathrm{~L}^{-1}$, v.v.: $1 \mathrm{mVs}^{-1}$. 
$\underline{\text { Análise morfológica da superfície dos diferentes substratos }}$

(a) Microscopia eletrônica de varredura

Nas Fig. 6-A a 6-C são apresentadas as micrografias feitas através do MEV para as superfícies de diferentes substratos de aço carbono ABNT 1008, sem e com fosfato de zinco ou tricatiônico.

A microscopia da superfície do aço carbono ABNT 1008, apenas polida até pasta diamante até $1 \mu \mathrm{m}$, Fig. 6-A, mostra a presença de inclusões na superfície da matriz.

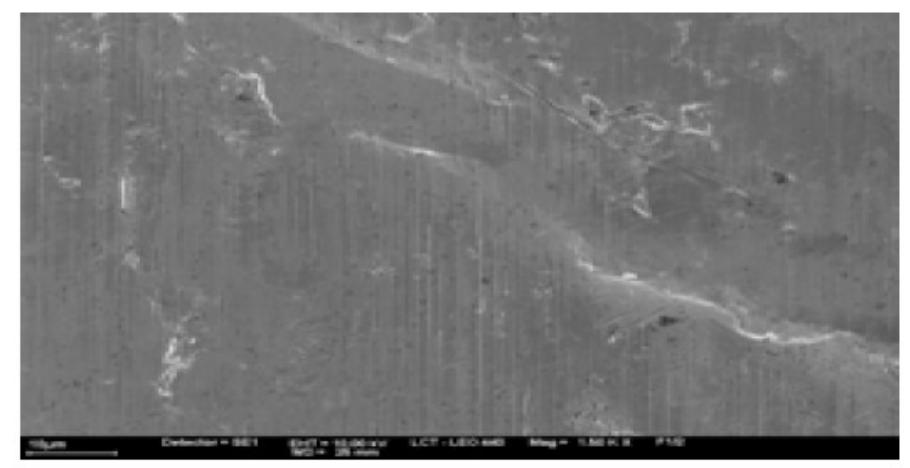

(Figura 6-A)

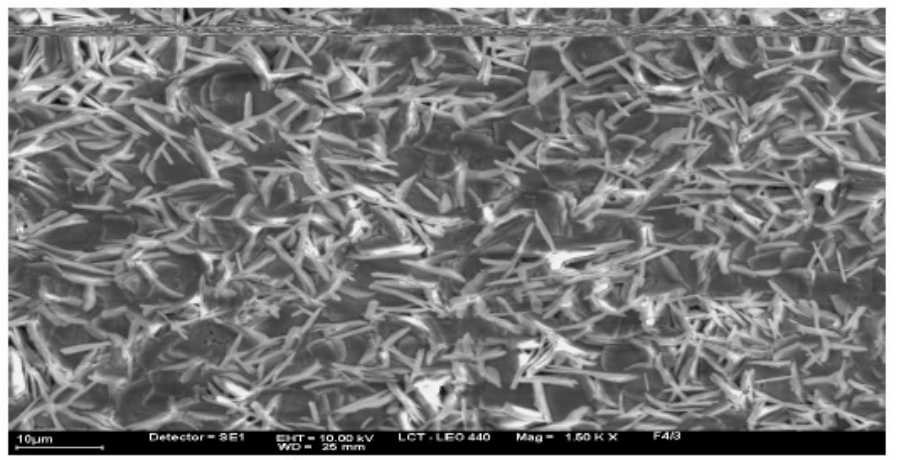

(Figura 6-B)

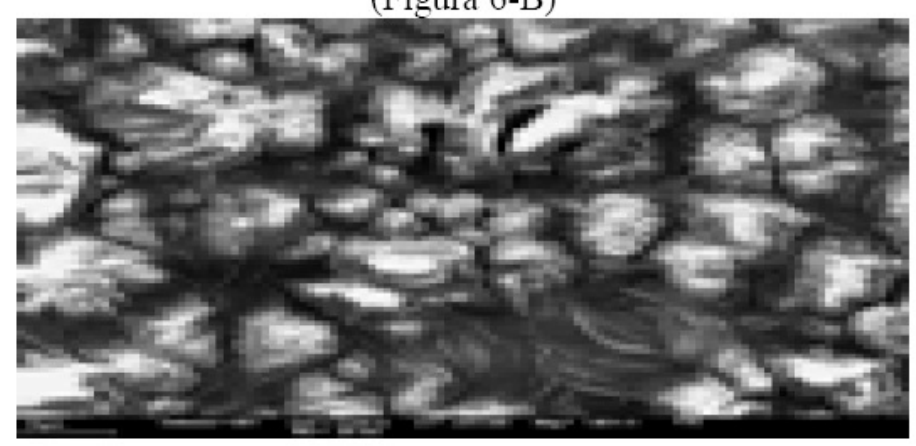

(Figura 6-C)

Figura 6. Microscopia eletrônica de varredura com aumento $1000 \mathrm{X}$ para o: (A) substrato de aço carbono ABNT 1008; (B) substrato de aço carbono ABNT 1008 contendo camada de fosfato de zinco; (C) substrato de aço carbono ABNT 1008 contendo camada de fosfato tricationico. 
Nas Fig. 6-B e 6-C são apresentadas as microscopias do substrato de aço com camadas de fosfato de zinco e tricationico, respectivamente. Verifica-se que a camada de fosfato zinco é gerada em forma de "agulhas", enquanto a camada de fosfato tricatiônico é na forma de "grãos", também conhecidos como "cogumelos". Estas microscopias evidenciam a melhor eficiência da camada de fosfato tricatiônico em relação à de zinco, já que a camada gerada de fosfato de zinco permite maior permeabilidade e conseqüentemente maior contato do eletrólito com o substrato de aço carbono, devido à existência de espaços entre as agulhas geradas na camada de fosfato de zinco.

\section{(b) Caracterização óptica}

Nas Fig. 7-A e 7-B são apresentadas as análises ópticas das superfícies de aço carbono ABNT 1008 contendo fosfato de zinco com TTA e fosfato tricatiônico com TTA, respectivamente.
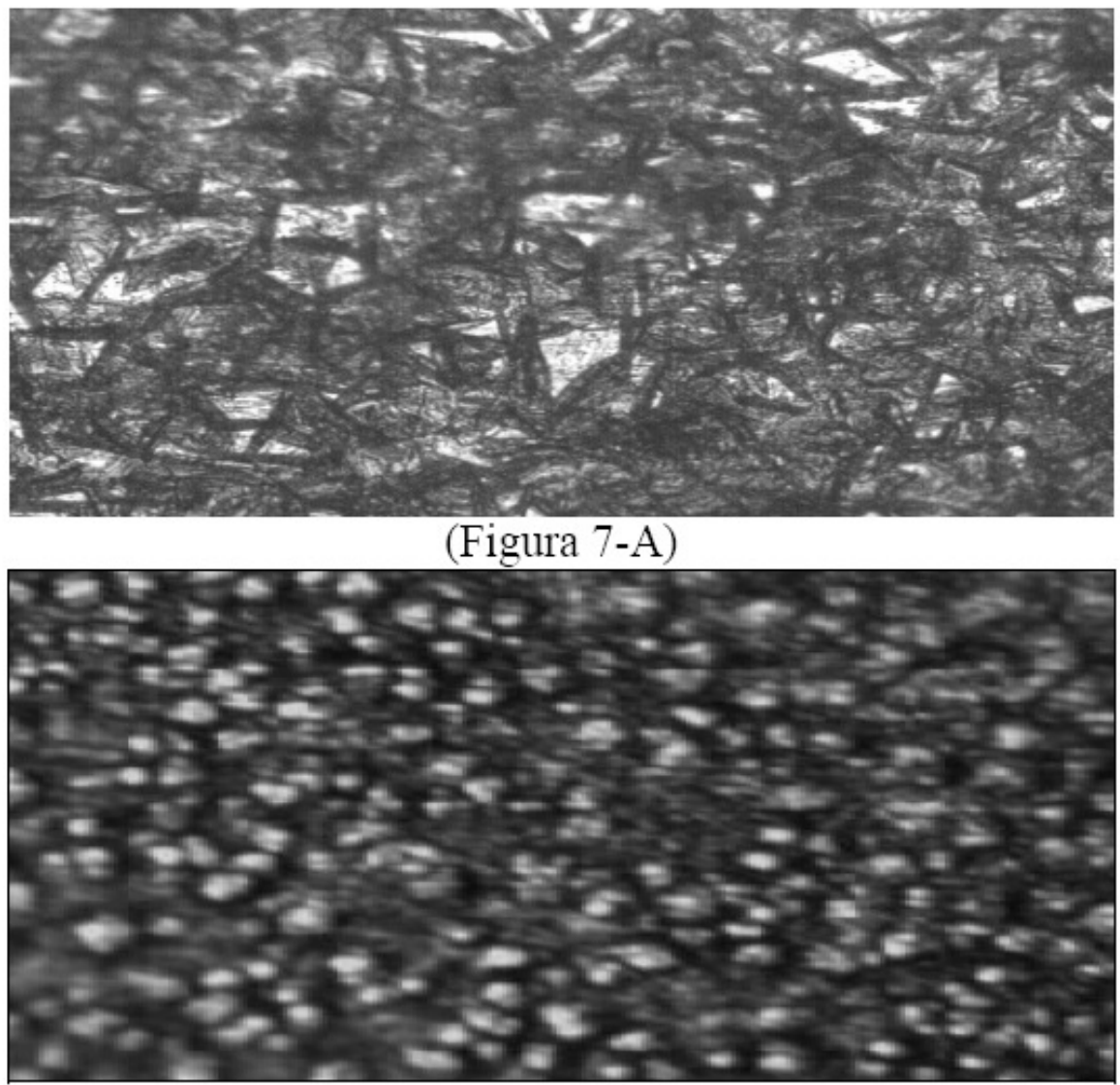

(Figura 7-B)

Figura 7. Análise óptica com aumento $500 \mathrm{X}$ da superfície de aço carbono ABNT 1008 contendo camada de: (A) fosfato de zinco com $[\mathrm{TTA}]=1.10^{-3} \mathrm{~mol} \mathrm{~L}^{-1}$; (B) fosfato tricatiônico com $[\mathrm{TTA}]=1.10^{-3} \mathrm{~mol} \mathrm{~L}^{-1}$.

As micrografias ópticas, Fig. 7-A e 7-B, do substrato de aço carbono ABNT 1008 contendo fosfato de zinco com TTA e fosfato tricationnico com TTA, evidenciam que na presença de TTA as camadas de fosfatos não se modificam quanto ao tipo de camada gerada, na superfície do substrato, em forma de "agulhas" ou "cogumelos", sugerindo que a atuação do TTA é a via de inibição 
do processo de oxidação das micro-áreas expostas do substrato de aço fosfatizado.

Espectroscopia de impedância eletroquímica

Nas Fig. de 8 a 9 são mostrados os diagramas de IE - Nyquist para o aço carbono ABNT 1008 sem e com camada de fosfato de zinco (PZn) e tricatiônico (Ptri), na ausência e presença de $[$ TTA $]=1.10^{-3} \mathrm{~mol} \mathrm{~L}^{-1}$ em meio de ácido $\left(\left[\mathrm{H}_{2} \mathrm{SO}_{4}\right]=0.1\right.$ mol L $\left.{ }^{-1}\right)$ e neutro $\left([\mathrm{NaCl}]=0.5 \mathrm{~mol} \mathrm{~L}^{-1}\right)$, respectivamente.

(a) meio ácido

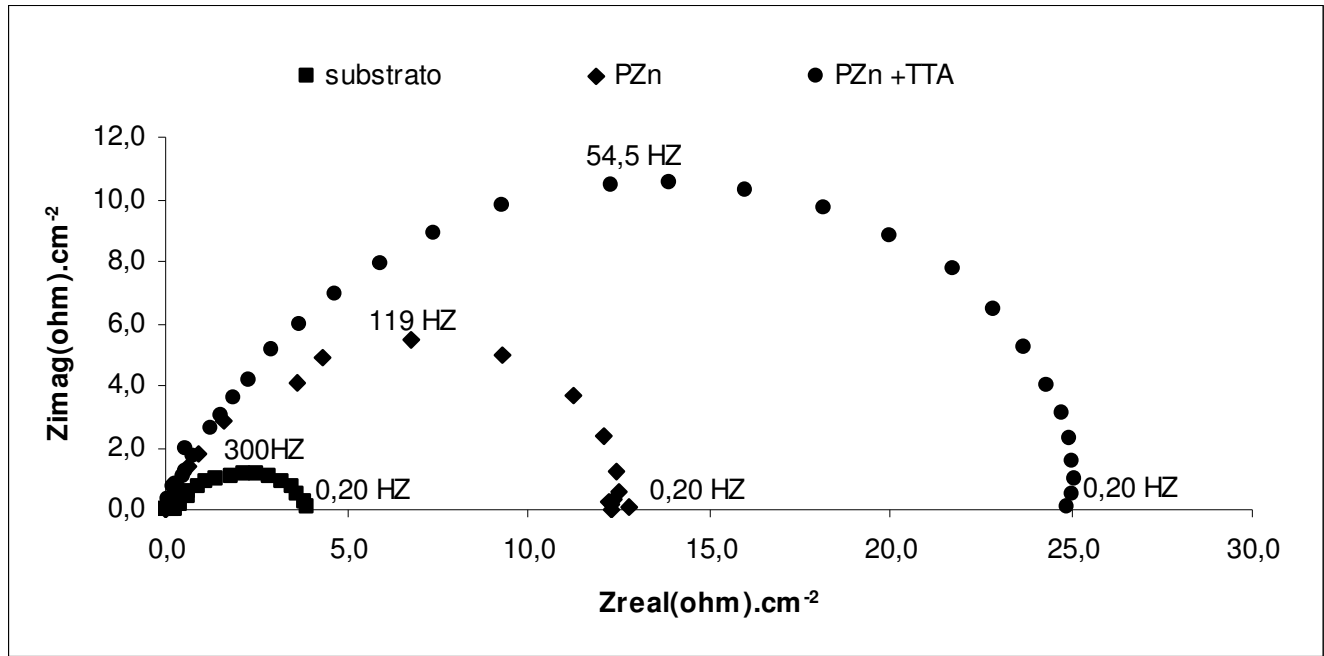

Figura 8-A. Diagramas de impedância eletroquímica (Nyquist) para diferentes substratos de aço $1008 \mathrm{em} \mathrm{H}_{2} \mathrm{SO}_{4} 0.1 \mathrm{~mol} \mathrm{~L}^{-1}$. $\eta=+50 \mathrm{mV}$ em relação ao $E_{\text {corr }}$ vs. ESM.

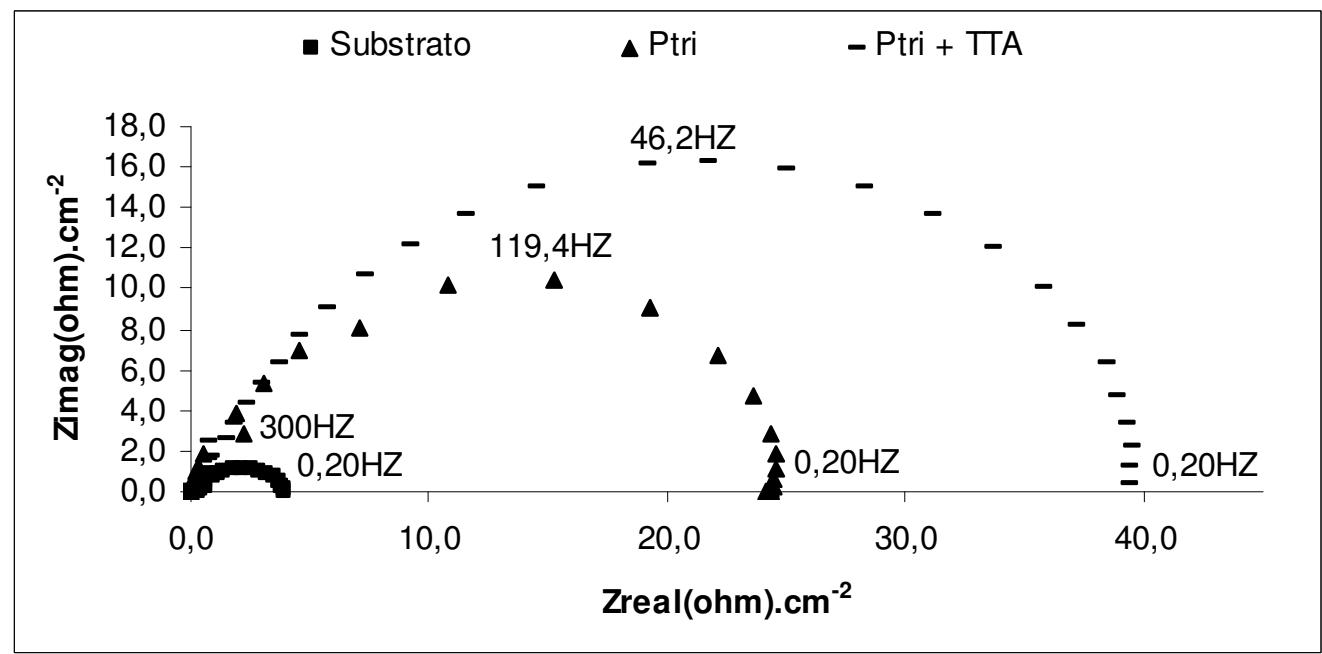

Figura 8-B. Diagramas de impedância eletroquímica (Nyquist) para diferentes substratos de aço $1008 \mathrm{em} \mathrm{H}_{2} \mathrm{SO}_{4} 0.1 \mathrm{~mol} \mathrm{~L}^{-1}$. $\eta=+50 \mathrm{mV}$ em relação ao $E_{\text {corr }}$ vs. ESM. 
Verifica-se nas Fig. 8-A e 8-B que a resistência de polarização ( $R p)$ dos diferentes substratos de aço $1008(\mathrm{~S})$ em meio de $\mathrm{H}_{2} \mathrm{SO}_{4} 0.1$ mol L ${ }^{-1}$, aumenta na seguinte seqüência:

$$
\begin{gathered}
\operatorname{Rp}(\mathrm{S})=4.1 \Omega \cdot \mathrm{cm}^{-2} \\
\operatorname{Rp}(\mathrm{S}+\mathrm{PZn})=12.3 \Omega \cdot \mathrm{cm}^{-2} \\
\operatorname{Rp}(\mathrm{S}+\mathrm{Ptri})=24.4 \Omega \cdot \mathrm{cm}^{-2} \\
\operatorname{Rp}(\mathrm{S}+\mathrm{PZn}+\mathrm{TTA})=24.9 \Omega \cdot \mathrm{cm}^{-2} \\
\operatorname{Rp}(\mathrm{S}+\mathrm{Ptri}+\mathrm{TTA})=39.3 \Omega \cdot \mathrm{cm}^{-2}
\end{gathered}
$$

Estes resultados mostram que a presença do TTA na camada fosfato aumenta a resistência à polarização do substrato (aço 1008), ou seja, atua na inibição da reação de oxidação do material metálico.

(b) em meio neutro

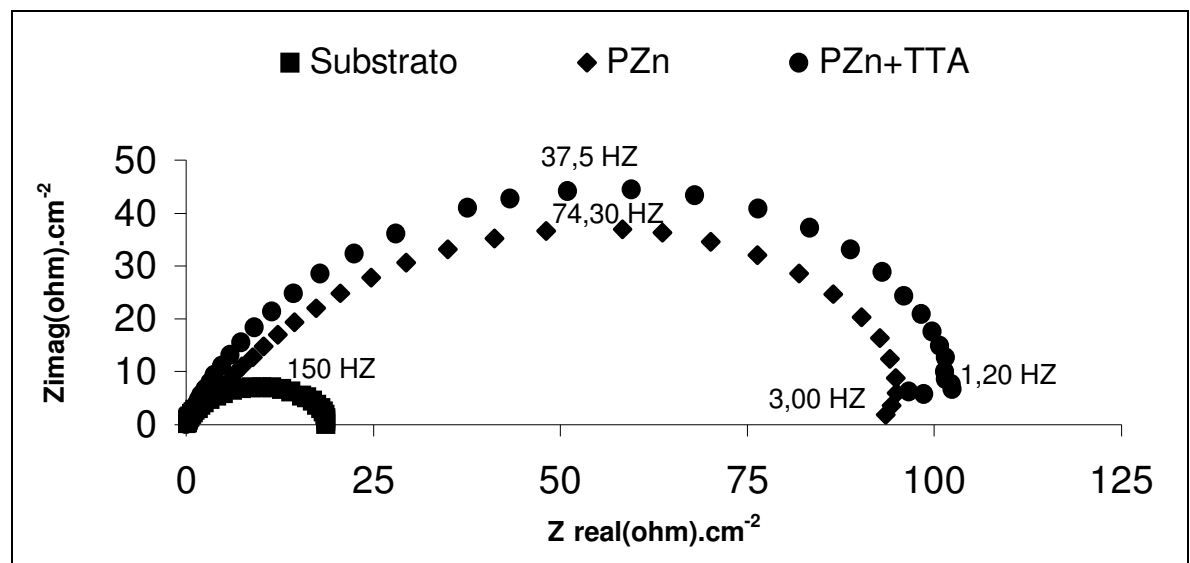

Figura 9-A. Diagramas de impedância eletroquímica (Nyquist) para diferentes substratos de aço $1008 \mathrm{em} \mathrm{NaCl} 0.5 \mathrm{~mol} \mathrm{~L}^{-1} . \eta=+50 \mathrm{mV}$ em relação ao $\mathrm{E}_{\text {corr }} \mathrm{vs}$. $\mathrm{Ag} / \mathrm{AgCl}$.

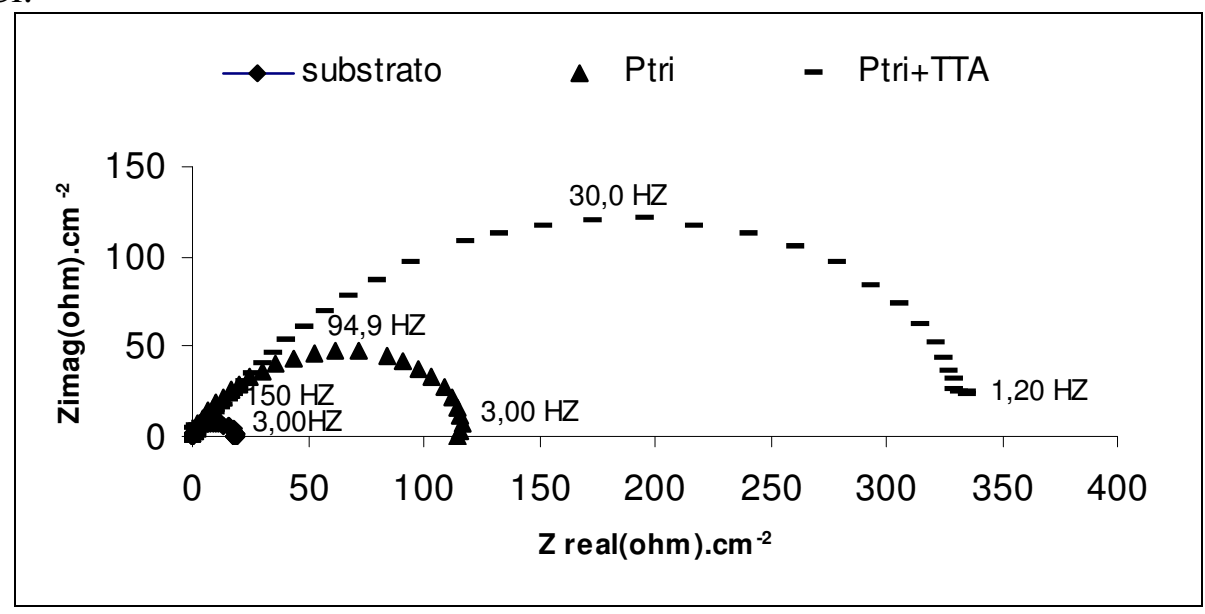

Figura 9-B. Diagramas de impedância eletroquímica (Nyquist) para diferentes substratos de aço $1008 \mathrm{em} \mathrm{NaCl} 0.5 \mathrm{~mol} \mathrm{~L}^{-1} \cdot \eta=+50 \mathrm{mV}$ em relação ao $\mathrm{E}_{\text {corr }} \mathrm{vs}$. $\mathrm{Ag} / \mathrm{AgCl}$.

Verifica-se nas Fig. 9-A e 9-B que a resistência de polarização (Rp) dos diferentes substratos de aço $1008(\mathrm{~S})$ em meio de $\mathrm{NaCl} 0.5 \mathrm{~mol} \mathrm{~L}^{-1}$, aumenta na mesma seqüência observada para o meio ácido (vide Fig. 8-A e 8-B), 
confirmando que as resistências de polarização dos substratos (aço 1008) contendo camada fosfato + TTA apresentam Rp maiores do que as dos outros substratos sem TTA.

$$
\begin{gathered}
\operatorname{Rp}\left(\mathrm{S}=18.5 \Omega . \mathrm{cm}^{2}\right. \\
\operatorname{Rp}(\mathrm{S}+\mathrm{PZn})=93.5 \Omega . \mathrm{cm}^{2} \\
\operatorname{Rp}(\mathrm{S}+\mathrm{Ptri})=114.5 \Omega . \mathrm{cm}^{2} \\
\operatorname{Rp}(\mathrm{S}+\mathrm{PZn}+\mathrm{TTA})=98.6 \Omega . \mathrm{cm}^{2} \\
\operatorname{Rp}(\mathrm{S}+\mathrm{Ptri}+\mathrm{TTA})=334 \Omega . \mathrm{cm}^{2}
\end{gathered}
$$

\section{Ensaios em câmara de "Salt Spray"}

Após todos os ensaios anteriores, algumas amostras de aço carbono ABNT 1008 contendo em sua superfície camadas de fosfato de zinco (PZn) e ou camadas de fosfato de zinco com TTA, foram pintadas com tinta pó poliéster branca, eletrostaticamente, e colocadas em câmara de Salt Spray por 500 horas a uma temperatura média de $45^{\circ} \mathrm{C}$.

Este teste foi executado com intuito de se verificar se os efeitos inibidores do TTA na camada de fosfato perduravam mesmo após aplicação da camada de tinta na peça metálica fosfatizada, sendo de grande relevância industrial, já que se poderia substituir a aplicação de fosfato tricatiônico pelo fosfato de zinco + TTA, com maior eficiência protetora à corrosão.

Os resultados destes testes são apresentados nas micrografias ópticas, Fig. 9, das superfícies dos diferentes substratos.

Nota-se na Fig. 9 que os riscos executados na superfície do aço pintada, de acordo com a norma ASTM D1654, após a exposição de 500 horas em câmara de Salt Spray, revelam rupturas de tinta e oxidação da peça metálica nas proximidades do risco executado na superfície pintada do aço carbono 1008 contendo fosfato de zinco (PZn), enquanto que na superfície pintada do aço carbono ABNT 1008 contendo fosfato de zinco $(\mathrm{PZn})+$ TTA, tal fato não é observado, confirmando que a camada de fosfato + TTA aumenta a proteção contra a corrosão do aço carbono 1008. 

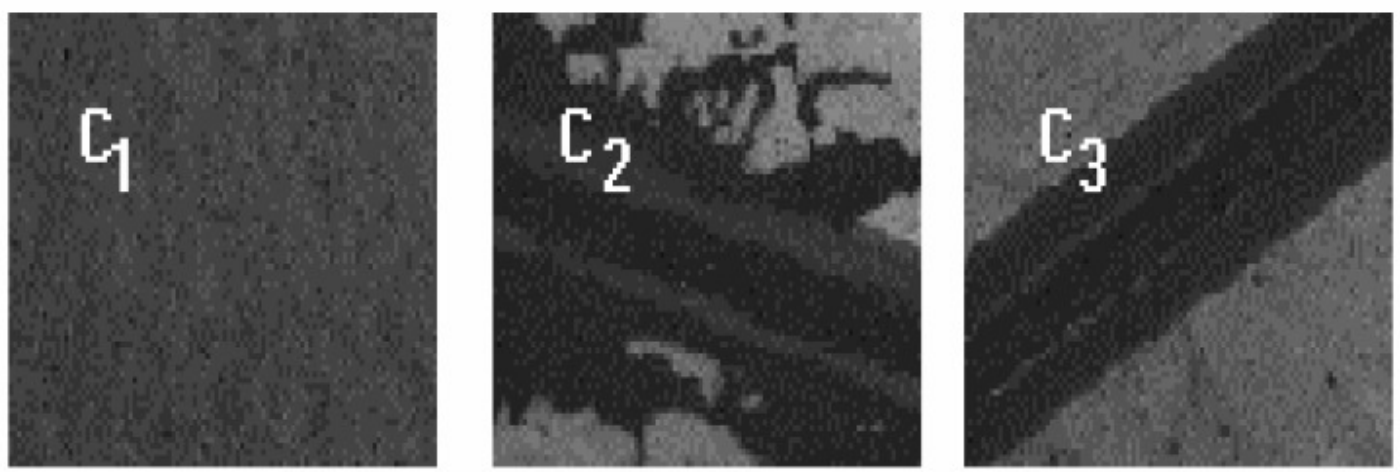

Figura 10. Micrografias ópticas com aumento de $100 \mathrm{X}$ de amostras de aço carbono 1008 fosfatizadas com PZn, na ausência e presença de TTA, revestidas com pintura eletrostática e expostas em câmara de Salt Spray por $500 \mathrm{~h}$ a $45{ }^{\circ} \mathrm{C}:\left(\mathrm{C}_{1}\right)$ ausência de TTA no PZn e sem exposição em câmara de Salt Spray; $\left(\mathrm{C}_{2}\right)$ ausência de TTA no PZn e com exposição em câmara de Salt Spray; $\left(\mathrm{C}_{3}\right)$ presença de TTA no PZn e com exposição em câmara de Salt Spray.

\section{Conclusões}

(1) Em presença de TTA, a massa das camadas de fosfatos de zinco e tricatiônico, diminui em função do tempo de imersão no banho ativador, provavelmente devido a competição na adsorção do TTA e do fosfato no substrato metálico;

(2) A análise das curvas de polarização anódica revela que em toda a faixa de potencial estudado ocorre uma diminuição no valor da densidade de corrente com adição do TTA na formulação dos fosfatos de zinco e tricatiônico, sugerindo uma melhor resistência à corrosão do substrato metálico;

(3) Os ensaios eletroquímicos e de Salt Spray indicam a viabilidade da troca do banho de fosfato tricatiônico pelo banho de fosfato de zinco na presença do TTA, uma vez que este último apresentou uma resistência a corrosão comparável a do banho de fosfato tricatiônico.

\section{Agradecimentos}

A Atlas - Eletrodomésticos Ltda. e a Eletra Química Ltda pelo suporte a pesquisa.

A FINEP, a FUNDAÇÃO ARAUCÁRIA(PR) e a UNICENTRO(PR) pelo apoio e suporte financeiro a pesquisa. 


\begin{abstract}
Resumo
As características inibidoras de corrosão do tolitriazol (TTA) para o aço carbono 1008, revestido por fosfato de zinco ou tricatiônico (Mn, $\mathrm{Zn}, \mathrm{Ni}$ ), nos meios de $\mathrm{H}_{2} \mathrm{SO}_{4} 0.1$ mol.L ${ }^{-1}$ e $\mathrm{NaCl} 0.5 \mathrm{~mol} \mathrm{~L}^{-1}$, foram investigadas por métodos físicos e eletroquímicos. Os resultados obtidos na ausência do inibidor TTA mostraram que as propriedades de proteção à corrosão do fosfato tricatiônico (Ptri) são melhores do que as observadas para o fosfato de zinco (PZn), provavelmente devido a porosidade existente na camada do PZn. As curvas de polarização anódicas apresentaram densidades de corrente $(\mathrm{j})$ menores para as peças de aço fosfatizadas com Ptri quando comparadas aos dos substratos sem fosfato e com PZn. Os resultados de impedância eletroquímica (IE) mostraram uma resistência de polarização $\left(R_{P}\right)$ maior para os eletrodos fosfatizados com Ptri. As medidas eletroquímicas das amostras de aço fosfatizadas, com PZn e/ou Ptri, na presença de $[\mathrm{TTA}]=1.10^{-3} \mathrm{~mol} \mathrm{~L}^{-1}$, apresentaram j menor e Rp maior do que as observadas para as amostras de aço fosfatizadas na ausência do TTA. No processo de fosfatização do aço carbono com PZn + TTA, observou-se j e Rp semelhantes as observadas nas amostras de aço fosfatizadas com Ptri sem TTA. Estes resultados sugerem que o banho de fosfato de zinco contendo [TTA] $=1.10^{-3} \mathrm{~mol} \mathrm{~L}^{-1}$ pode substituir o mundialmente consagrado banho industrial de fosfato tricatiônico. Os ensaios em câmara de Salt Spray de amostras de aço fosfatizadas com PZn e PZn + TTA, pintadas com tinta pó poliéster branca, confirmaram os resultados eletroquímicos obtidos.
\end{abstract}

Palavras chave: tolitriazol, corrosão, fosfatização e inibidores.

\title{
Referências
}

1. V. Gentil, Corrosão, Rio de Janeiro, 1987.

2. D.Weng, P.Jokiel, A.Uebleis, H. Boehni, Surface and Coatings Technology 88 (1996) 147-156.

3. M. Murphy, Metal finishing, (1998) 10-30.

4. B. Patacek, F. Dalard, J.J. Rameau, Surface and Coatings Technology 8 (1196) 277-283.

5. M. Wolpers, J. Angeli, Applied Surface Science 179 (2001) 281-291.

6. He Delaing, Chen Fancai, Zhai Anhong, Nie Lihua, Yao Shouzhuo, Thin Films 382 (2001) 262-270.

7. A.W. Brace, P.G. Sheasky, Technology Ltd, $2^{\text {nd }}$ ed., England, 1998.

8. P. Hivart, B. Hauv, J.P. Bricout, J. Oudim, Tribology International 8 (1997) 561-570.

9. $\quad$ T.S.N. Sankara Narayanan, Metal Finishing (1996) 86-90.

10. D.B. Freeman, Phosphating and Metal Pre-treatment, Woodhead-Faulkner Ltd., Cambridge, England, 1986.

11. T.Sugama, J. Coatings Technology, 66 (11) (1994) 43.

12. M.F. Oliveira, Caracterização Fisicoquímica do Aço Carbono Fosfatizado em $\mathrm{H}_{2} \mathrm{SO}_{4}$ 0,1 Mol. $L^{-1}$, Monografia de "Lato Sensu" apresentada ao DEQUnicentro-PR Guarapuava, 2003, p. 52.

13. M.T. Cunha, Estudo do comportamento dos inibidores benzotriazol $e$ tolitriazol na oxidação de matériais ferrosos em meio de ácido sulfúrico, Dissertação de mestrado apresentada ao IQUSP-SP, São Paulo, 2003, p. 114. 